\title{
Paulo Freire e a Geografia: diálogos com Milton Santos
}

\section{Paulo Freire and Geography: conversations with Milton Santos}

Sandro de Castro Pitano*

Rosa Elena Noal **

\begin{abstract}
Resumo:
O artigo é resultado de uma pesquisa bibliográfica que analisou a Geografia presente no pensamento de Paulo Freire, articulando um encontro dialógico com Milton Santos. Investiga a afinidade epistemológica entre os autores, verificando as diferentes formas de abordagem geográfica percebidas no pensamento freiriano. Busca identificar a ocorrência de conceitos clássicos da Geografia nos escritos de Freire, como espaço, território, região e lugar, além de compreender os diferentes sentidos que o mesmo atribui ao vocábulo "geografia". O diálogo entre os autores se amplia ao problematizar o horizonte existencial do ser humano na sociedade contemporânea: sujeito social e cidadão, respectivamente. As conclusões evidenciam que Paulo Freire utiliza os principais conceitos da Geografia ao longo da sua obra e que a afinidade com Milton Santos extrapola os elementos conceituais evidenciados no texto.
\end{abstract}

\section{Abstract:}

The article is the result of a bibliographic research that analyzed this Geography at the thought of Paulo Freire, combining a dialogical encounter with Milton Santos. Investigates the epistemological affinity between authors, checking the different forms of geographical approach perceived in Freirian. Seeks to identify the occurrence of classical concepts of geography in the writings of Freire, such as space, territory, region and place, and understand the different meanings that it attaches to the word "geography". The dialogue between the authors is extended to discuss the existential horizon of the human being in contemporary society: social subject and citizen, respectively. The findings show that Paulo Freire uses key concepts of geography throughout their work and that the affinity with Milton Santos extends beyond the conceptual elements highlighted in the text.

\begin{abstract}
* Doutor em Educação, professor do Instituto de Ciências Humanas da Universidade Federal de Pelotas - UFPel.

** Doutora em Geografia, professora do Instituto de Ciências Humanas da Universidade Federal de Pelotas - UFPel..
\end{abstract}

Palavras-chave:

Paulo Freire, Geografia, Milton Santos, Cidadão

Key-Words:

Paulo Freire,

Geography, Milton Santos,

Citizen 


\section{INTRODUÇÃO}

$\mathrm{O}$ texto desenvolve uma análise sobre a Geografia presente no pensamento de Paulo Freire, tendo como referência a obra de Milton Santos, promovendo um diálogo epistemológico entre ambos. Inicialmente, são destacadas algumas marcas da afinidade entre os autores, seguida da análise das diferentes formas de abordagem geográfica percebidas no pensamento freiriano, considerando a totalidade de seus livros, inclusive os dialogados. A seguir, busca identificar a ocorrência de conceitos clássicos da Geografia nos escritos de Freire, como espaço, território, região e lugar, além de compreender os diferentes sentidos que o mesmo atribui ao vocábulo "geografia". Por fim, ensaia um diálogo conceitual entre Paulo Freire e Milton Santos, o qual se amplia ao problematizar o horizonte existencial do ser humano na sociedade contemporânea: sujeito social e cidadão, respectivamente.

Estudar o pensamento de Paulo Freire é sempre um exercício desafiador, considerando aspectos como a abrangência e o nível de aprofundamento que caracterizam seus escritos. É abrangente, tanto no sentido das diversas ciências que nele encontram fonte de conhecimento, como, também, pelo enfrentamento corajoso de problemas sociais do cotidiano. Ambas as perspectivas se complementam em um autêntico trabalho interdisciplinar, talvez até transdisciplinar, que não admite dissociação entre teoria e prática. $\mathrm{O}$ aprofundamento analítico se torna mais explícito na medida em que, no e com seu pensamento, assumimos, leitores e pesquisadores de sua obra, o compromisso de compreendê-lo com a devida rigorosidade, evitando a superficialidade que Freire tanto combateu.

O desafio se robustece face à ampla gama de estudos que, nas mais variadas áreas e contextos, têm sido realizados sobre a obra freiriana. Assim, destaca-se a preocupação de evitar "chover no molhado", mesmo que a cada repisar sejamos enriquecidos, sujeitos em processo de vir-a-ser que somos por suas análises permanentemente redimensionadas. Tal é o conjunto de concepções que embasa e delineia este estudo, apresentado em forma de artigo. Portanto, investigar o pensamento de Paulo Freire, buscando evidenciar e compreender nele a presença da Geografia, eis o objetivo geral que se desdobra, com a participação do geógrafo Milton Santos, em um ensaio dialógico entre ambos.

1. VIDA E PENSAMENTO, AS AFINIDADES ENTRE PAULO FREIRE E MILTON SANTOS
Ao analisarmos a trajetória vivencial, percebemos que Freire e Santos possuem muitas afinidades, sendo diversos os pontos de aproximação que propiciam um estudo dialógico como este. A seguir, elencaremos alguns desses aspectos, tecendo breves comentários que visam mais explicitar do que, propriamente, aprofundar cada um em particular. Para tanto, serão consideradas duas dimensões principais, a partir das quais serão elencados aspectos específicos: a história de vida (1) e o pensamento (2).

\subsection{História de vida}

O contexto espacial e temporal em que nasceram: o nordeste brasileiro na década de 1920. Paulo Freire nasceu em Recife, Pernambuco, em 1921; Milton Santos nasceu em Brotas de Macaúbas, Bahia, em 1926.

A experiência escolar e acadêmica: alunos professores e a formação em Direito. Tanto Freire como Santos cursaram o período ginasial em escolas particulares, período em que iniciaram seus passos na docência, não apenas por prazer, mas, também, pela necessidade econômica. Freire ensinou Português e Santos, Geografia. Na faculdade, ambos cursaram e se formaram em Direito, profissão que, curiosamente, não chegaram a exercer.

A docência e a concomitante atuação política: ambos desenvolveram ações junto aos governos municipal, estadual e federal, ao mesmo tempo em que exerciam a docência. Freire atuou em órgãos como o Conselho Consultivo de Educação Municipal de Recife, Divisão de Cultura e Recreação da Prefeitura de Recife e o Conselho Estadual de Educação de Pernambuco, além de representar o governo federal junto a SUDENE e dirigir o Programa Nacional de Alfabetização implementado a partir de 1963. Sua experiência acadêmica se inicia em 1947 junto a Escola de Serviço Social de Recife, mesmo ano em que iniciou as atividades no SESI . Milton Santos dirigiu a Imprensa Oficial do Estado da Bahia, presidiu a Fundação de Planejamento Econômico da Bahia e foi candidato a vereador por Salvador. Foi professor da Universidade Católica da Bahia.

Prisão, exilio e experiência internacional: Paulo Freire e Milton Santos foram presos e exilados como consequência do golpe civil-militar de 1964 no Brasil. Milton Santos ficou cerca de cem dias preso e treze anos (1964-1977) exilado no exterior, atuando principalmente como professor em países como França (cerca de sete anos), Estados Unidos, Canadá, Venezuela, Peru, Tanzânia e Nigéria. Na Universidade 
de Toulouse (França), lecionou por três anos. Na década de 1970, período intelectualmente bastante fértil para Milton Santos, estudou e trabalhou em universidades no Peru, na Venezuela, nos Estados Unidos (país no qual entre 1975 e 1976 foi pesquisador no Massachusetts Institute of Technology) e no Canadá. Em 1977 retornou para o Brasil, atuando como consultor e professor assistente, professor na Universidade Federal do Rio de Janeiro e, a partir de 1984, professor titular na Universidade de São Paulo (USP). Já Paulo Freire esteve preso cerca de setenta dias divididos em dois momentos, enfrentando um período de exilio um pouco maior em relação a Milton Santos, quinze anos (1964-1979/80). Após uma rápida passagem de três semanas pela Bolívia, seguiu para o Chile onde permaneceu por quase cinco anos, primeiro como funcionário do Instituto de Desenvolvimento Agropecuário (INDAP) e depois junto ao Instituto de Capacitação e Reforma Agrária (ICIRA). Após, Estados Unidos, como professor em Harvard (1969) e Suíça, onde permaneceu por dez anos (1970-1980) como consultor especial do Departamento de Educação do Conselho Mundial de Igrejas e professor da Universidade de Genebra.

Retorno ao Brasil: ambos atuaram como professores em universidades de São Paulo. Milton Santos na USP - Universidade de São Paulo e Paulo Freire na UNICAMP - Universidade Estadual de Campinas e PUC-SP - Pontifícia Universidade Católica de São Paulo

\section{$1.2 \mathrm{O}$ pensamento}

a) A opressão sentida e combatida: opressão de classe, em Freire e opressão de raça, em Santos, marcantes em suas obras e entrevistas.

b) A dimensão utópica: ambos revelam otimismo diante das condições sociais. Conforme salienta Santos (2001, p.18):

De fato, se desejamos escapar à crença de que esse mundo assim apresentado é verdadeiro, e não queremos admitir a permanência de sua percepção enganosa, devemos considerar a existência de pelo menos três mundos num só. O primeiro seria o mundo tal como nos fazem vê-lo: a globalização como fábula; o segundo seria o mundo tal como ele é: a globalização como perversidade; e o terceiro o mundo como ele pode ser: uma outra globalização.

Em entrevista publicada sob o título "Território e sociedade: entrevista com Milton Santos", quando questionado sobre a pertinência da utopia na atualidade, Santos (2000, p.71) enfatiza a sua importância como possibilidade a ser construída "a partir do que já existe como germe e, por isso, se apresenta como algo factível”. Assim como Freire, assume o desafio de partir da realidade presente e, atuando sobre ela, construir o ideal almejado historicamente. Freire (2003, p.239) afirma que um mundo ideal, "feito de utopias", não será alcançado apenas por meio do sonho: "sonhar com este mundo, porém, não basta para que ele se concretize. Precisamos de lutar incessantemente para construí-lo". Assim como Santos, nutre a convicção que "o utópico não é o irrealizável", pois a utopia "é a dialetização dos atos de denunciar e anunciar, o ato de denunciar a estrutura desumanizante e de anunciar a estrutura humanizante", constituindo-se em "um compromisso histórico" (FREIRE, 1980, p.27).

c) Aposta no "pólo fraco": oprimidos e pobres. A construção do sujeito como caminho, sujeito social (Freire) e cidadão (Santos). Milton Santos foi um intelectual combatente que desenvolveu uma análise radical da origem técnica e política do fenômeno da globalização. Enfocou a globalização como ideologia de um presente perverso e de um futuro que, analisado dialeticamente, pode vir a ser promissor. Tratou-a como globalitarismo (união dos conceitos de globalização e totalitarismo). Influenciado pelas ideias de Sartre sobre a experiência da escassez, acreditava que os pobres seriam os deflagradores de uma nova globalização. De maneira semelhante, Freire sustenta que apenas o oprimido pode libertar a si e ao opressor. Sob uma visão crítica, a libertação contempla a negatividade "forte", que encontra somente no polo fraco (o oprimido) o poder de romper: "Por isso é que somente os oprimidos, libertando-se, podem libertar os opressores. Estes, enquanto classe que oprime, nem libertam, nem se libertam" (FREIRE, 2002e, p.43).

d) Influência teórica: são muitas as referências teóricas que compartilham e influenciam seu pensamento. Eis alguns autores com presença em suas obras: Marx, Engels, Gramsci, Hegel, Husserl, Lukács, Sartre, Whitehead, Goldmann, Heller, Kosik, Habermas, Mannheim, Marcel, Merleau-Ponty, Ortega y Gasset, Amilcar Cabral e Fromm, entre outros. Cabe mencionar que Milton Santos cita uma passagem da "Pedagogia do Oprimido", de Paulo Freire na obra "O espaço do cidadão” (SANTOS, 2007, p.99), publicada em 1987. Por sua vez, em "Aprendendo com a própria história", obra dialogada com Sérgio Guimarães, Freire (1987, p.23) destaca que no período em que representou o governo federal junto a SUDENE, ainda nos anos de 1950, reunia-se com um irmão de Milton Santos, Nailton Santos, então diretor de recursos humanos daquele órgão. Referiu-se a Milton Santos como "esse grande geógrafo brasileiro que agora está na 
USP’. Santos sofreu influência marcante, no início de sua carreira, de geógrafos franceses como Pierre George, Michel Rochefort e, especialmente, de Jean Tricart, por intermédio do qual teve contato com as ideias de Marx, como explica: "Eram mestres que me influenciaram profundamente como Jean Tricart, que foi a pessoa que mais me impressionou, e, de segunda mão, me passou um marxismo" (SANTOS, 2000, p.93).

e) A aposta no lugar como instância de resistência ao capitalismo: o contexto (Freire) e o cotidiano (Santos). Nas dezesseis obras de Freire analisadas, a palavra contexto aparece em todas, num total de quatrocentos e quarenta e duas vezes: contexto social, concreto, teórico, real, de empréstimo, local, tradicional, histórico, de vida, pedagógico, imediato, cultural. Para Santos (2002a, p.339), o cotidiano, relacionado ao lugar, representa outra relação existencial, oposta à sistêmica: "a ordem local funda a escala do cotidiano, e seus parâmetros são a co-presença, a vizinhança, a intimidade, a emoção, a cooperação e a socialização com base na contiguidade".

Em relação ao horizonte existencial do ser humano na sociedade, Freire e Santos aparentam postular concepções diferentes. Enquanto um, implicitamente, idealiza um sujeito social, o outro aposta no cidadão. Porém, ao analisar o pensamento de ambos, percebe-se que compartilham noções semelhantes, embora a terminologia usada seja diversa. Por isso é possível falar em encontros e desencontros, ainda que aparentes, entre os dois.

Milton Santos embasa as reflexões sobre a ocupação e a transformação do espaço em uma abordagem geográfica radicalmente crítica e comprometida com as problemáticas sociais do tempo presente. Com o advento e aprimoramento das técnicas, cujo processo em si não pode ser responsabilizado pelo nosso modo de vida exploratório e poluidor, a humanidade foi gradativamente transformando o espaço vivido. Primeiro, de forma lenta e sutil, imprimindo maior velocidade e profundidade à medida que as técnicas, entendidas como o "conjunto de meios instrumentais e sociais, com os quais o homem realiza sua vida, produz e, ao mesmo tempo, cria espaço" (SANTOS, 2002a, p. 29) foram sendo aprimoradas. Os objetos contidos em nosso meio não mais se determinam por si mesmos, sendo valorados e organizados segundo a lógica da ação humana para o seu uso. E o meio (antes "natureza") acaba se constituindo num sistema de objetos em que tudo possui intencionalidade e valor.

Em síntese, no meio natural as relações humanas com a natureza eram pautadas pela "harmonia socioespacial [...] respeitosa da natureza herdada, no processo de criação de uma nova natureza" (SANTOS, 2002, p.236). Com o advento da mecanização, a ação humana sobre o espaço (e não mais sobre a natureza em seu sentido original) se tornou cada vez mais poderosa. Esta artificialização do modo de interferir no espaço, transformando-o, funda o que o geógrafo brasileiro denomina de meio técnico:

Os objetos técnicos e o espaço maquinizado são locus de ações
"superiores", graças a sua superposição triunfante às forças
naturais. Tais ações são, também, consideradas superiores pela
crença de que ao homem atribuem novos poderes - o maior
dos quais é a prerrogativa de enfrentar a Natureza, natural ou já
socializada, vinda do período anterior, com instrumentos que
já não são prolongamento do seu corpo, mas que representam
prolongamentos do território, verdadeiras próteses. Utilizando
novos materiais e transgredindo a distância, o homem começa
a fabricar um tempo novo, no trabalho, no intercâmbio, no lar.
Os tempos sociais tendem a se superpor e contrapor aos tem-
pos naturais (SANTOS, 2002a, p.236).

Desde o vertiginoso desenvolvimento científico percebido após a II Guerra Mundial, as técnicas vêm se tornando cada vez mais eficientes em relação à intencionalidade do mercado, seu gestor principal. Aliadas a capacidade informacional que multiplica e aprofunda a ação transformadora do espaço, globalizando as relações de produção e consumo, as técnicas transformam-se "no meio de existência de grande parte da humanidade" (SANTOS, 2002a, p.239).

Salientando o caráter ideológico do conhecimento e a necessidade de problematizá-lo, Paulo Freire ratifica o pensamento de Santos (2002a, p.238), para quem a "união entre técnica e ciência vai dar-se sob a égide do mercado". Entendem ambos, que o poder do capital implica em transformações espaciais a partir de intencionalidades unilaterais, dirigidas por uma ótica exploratória e sem limites.

Milton Santos dedicou uma obra inteira para analisar a cidadania como condição do indivíduo nas modernas sociedades capitalistas. Intitulada "O espaço do cidadão" (SANTOS, 2007) a obra problematiza a cidadania a partir do espaço, categoria de análise central da ciência geográfica e, segundo o próprio autor, seu objeto de estudo. O geógrafo afirma que em países como o Brasil, "em lugar do cidadão formou-se um consumidor, que aceita ser chamado de usuário" (SANTOS, 2007, p.25), refém de uma insatisfação permanente, a qual garante a sua "dependência em relação aos novos objetos" disponibilizados pelo mercado em ritmo cada vez mais intenso.

O mais grave é a percepção de que "as empresas hegemônicas produzem o consumidor antes mesmo de produzir os produtos", pois, no funcionamento sistêmico da sociedade, "a produção do consumidor, hoje, precede à produção 
dos bens e dos serviços" (SANTOS, 2001, p.48). O consumo, dado o seu pragmatismo, acaba corporificando um desejo sedutor de poder, aproximando e identificando o cidadão com o consumidor. A proteção ao consumidor, codificada em manuais, nunca problematiza o consumo; apenas induz a comprar mais, conferindo uma atmosfera de tranquilidade, no intuito de aparentar uma participação ativa na sociedade. Porém, trata-se de uma participação harmônica ao sistema: quanto mais participantes ativos houver, mais ele se fortalecerá. Comparativamente, o consumo é o ópio pós-moderno, adorado nos shopping centers, condicionando o comportamento coletivo e responsável pela alienação, conduzindo ao individualismo sem limites.

A identificação, aparentemente, inocente entre consumidor e cidadão não deixa margem para o posicionamento crítico diante das contradições sociais, especialmente a desigualdade. A cidadania continua como condição universal a ser alcançada e o consumo é o meio de atingi-la. Ele se torna vocação e esperança, atiçado pela multiplicação das necessidades. Logo, saciar o desejo de consumir é algo impossível, bem ao gosto do capitalismo. Através da facilidade de crédito amplamente anunciada, o consumo é acessível à quase totalidade das pessoas, incluindo aquelas em situação de pobreza, que veem as classes melhor favorecidas como um exemplo a ser seguido. A cidadania se consolida por meio do consumo, clamando por mais inclusão, esperançosa da plenitude e da igualdade anunciadas pela propaganda. De direitos sociais às conquistas pessoais: mesmo que pequenas, em função das condições dificeis, revelam a postura ativa no convívio social ao alcance de todos.

Portanto, no âmbito do horizonte existencial na sociedade, ambos problematizam a cidadania, condição do cidadão prevista nas democracias modernas. Entendemos que o desencontro é aparente em razão da distinta abordagem conceitual que utilizam, pois propõem semelhante enfrentamento aos limites políticos e mesmo concretos que a cidadania possui. Sustentamos a ideia de que ambos propugnam, como horizonte, o sujeito social.

Modernamente, cidadão significa o indivíduo em gozo dos direitos civis e políticos em um Estado. Entre eles, direitos que, na prática, correspondem a deveres, como no caso dos brasileiros, o de votar. A cidadania (condição do cidadão) é uma palavra que se presta a empregos nos mais variados jogos de linguagem e de poder, mas, de forma geral, tem configurado o pertencimento do indivíduo a um Estado, regulamentador dos direitos e deveres individuais e coletivos. A dimensão social da cidadania explicita o maior abismo entre o formalmente previsto e o efetivamente alcançado. A desigualdade das condições econômicas entre os indivíduos constitui-se em um impeditivo concreto para a fruição do que é previsto em lei, inclusive quanto aos aspectos políticos e civis. A concretude da cidadania, entendida como a correspondência entre o legal e o efetivo, continua dependente do fator material.

Como núcleo representativo da existência social, o cidadão deve concretizar os anseios sistêmicos e por isso é formado em consonância aos princípios do trabalho e da participação previstos e esperados pela organização política em vigor. Sem dúvida, havendo um compromisso político da educação, ele é, no meio oficial, conformar o indivíduo ao sistema, garantindo a sua reprodução. Nessa ótica, a educação não deve contribuir para o desenvolvimento da capacidade crítica, pois o desvelamento ideológico das bases de sustentação das relações sistêmicas pode comprometer a sua existência. Em síntese, é finalidade da educação oficial construir a cidadania, ampliando o funcionamento político da sociedade como está sendo, assentada na democracia representativa.

Por sua vez o sujeito social, identificado como meta existencial no pensamento de Paulo Freire, é fruto dos caminhos de aprendizagens percorridos pelo ser humano, superando estágios de consciência, ao mesmo tempo em que age, ativamente, em seu contexto. Um caminho que jamais é linear, sem constrições, e, menos ainda, pré-determinado. É movimento humano na história de suas relações cada vez mais conscientes com os outros e com o que ocorre no mundo. Embora não seja encontrado, explicitamente, na obra de Freire, o termo sujeito social, o uso de outras expressões com afinidade semântica, tais como sujeito histórico, sujeito da decisão, sujeito cognoscente, sujeito da transformação e sujeito político, revelam-no presente, ainda que de maneira implícita.

Diferentes dos cidadãos, os sujeitos sociais questionam a legitimidade do contrato: compreendendo, com olhar crítico, a insuficiência do mesmo com relação às garantias mínimas para a libertação coletiva, assumindo a tarefa de participar, ativamente, da elaboração dos estatutos que regem suas próprias vidas, fazem da ingerência política um princípio radical. Separam democracia de capitalismo, considerando, responsavelmente, a ordem social como espaço e tempo de liberdade em processo, negação dos dogmatismos, quaisquer que sejam as suas faces. Nessa dimensão complexa, embora o sujeito não se identifique, plenamente, com o seu significado na modernidade, o pensamento crítico é dele constituinte, residindo, aí, uma das fontes de defesa diante da opressão social. Enquanto o cidadão deve ser incluído e emancipado 
dentro de um sistema que pode, no máximo, operar reformas conservadoras, o sujeito social se constitui na transgressão intersubjetiva, que compreende, na necessidade de ser mais, a tendência sujeitadora do ordenamento político e econômico, o que pode conduzi-lo à ação transformadora.

Em sua concepção de Mundo, Freire revela uma postura dialética de interpretação das contradições sociais. A contradição dialética se revela como responsável pelo surgimento de um sujeito novo, que se torna outro daquilo que era a partir do movimento contraditório dos seus predicados. Convicto de seu posicionamento sobre a sociedade, "insatisfeito com o mundo de injustiças que está ấ” (FREIRE, 2002f, p.91), o autor opta pelo homem sujeito, horizonte formativo da autêntica "educação para a liberdade", única opção a ser seguida, em se tratando de educadores que acreditam no "futuro como possibilidade e não determinismo" (2002f, p.92), sabedores de que, se o amanhã fosse um porvir pré-concebido, sucessão de acontecimentos inevitáveis, caberia tão somente às pessoas se prepararem para a adaptação.

Segundo Freire, para escrever a história e assumir-se como sujeito capaz, o ser humano precisa ter "consciência de si” e, para isto, a educação é fundamental, no sentido de viabilizar a superação de posturas deterministas (mecânica) e/ou voluntaristas (idealista) diante da realidade:

Na compreensão da história como possibilidade, o amanhã é problemático. Para que ele venha é preciso que o construamos mediante a transformação do hoje. Há possibilidades para diferentes amanhãs. A luta já não se reduz a retardar o que virá ou a assegurar sua chegada; é preciso reinventar o mundo. A educação é indispensável nessa reinvenção. Assumirmo-nos como sujeitos e objetos da história nos torna seres da decisão, da ruptura. Seres éticos (FREIRE, 2000a, p.40).

Otimista, Freire sustenta uma forte crença na capacidade que homens e mulheres possuem de superar as suas "situações limite", a exploração que foi se constituindo historicamente. Mostra, também, que transformar a realidade, implicando em libertar oprimidos e opressores, é a preocupação responsável por engendrar a Pedagogia do Oprimido, como pedagogia humanista e libertadora.

É interessante destacar que a obra de Milton Santos também revela uma análise possibilista de ruptura com o individualismo do cidadão consumidor, usuário e que passa, necessariamente, por um processo semelhante à conscientização defendida por Freire. Nas palavras de Santos (2001, p.138-9):

A atual experiência de escassez pode não conduzir imediatamente à desejável expansão da consciência. E quando esta se impõe, não o faz igualmente, segundo as pessoas. Visto esque- maticamente, tal processo pode ter, como primeiro degrau, a preocupação de defender situações individuais ameaçadas e que se deseja reconstituir, retomando o consumo e o conforto material como o principal motor de uma luta, que, desse modo, pode se limitar a novas manifestações de individualismo. É num segundo momento que tais reivindicações, fruto de reflexão mais profunda, podem alcançar um nível qualitativo superior, a partir de um entendimento mais amplo do processo social e de uma visão sistêmica de situações aparentemente isoladas. $\mathrm{O}$ passo seguinte pode levar à decisão de participar de uma luta pela sua transformação, quando o consumidor assume o papel de cidadão. Não importa que esse movimento de tomada de consciência não seja geral, nem igual para todas as pessoas. O importante é que se instale.

O que poderá gerar a reflexão anunciada pelo autor, responsável pela transformação da compreensão de mundo do sujeito? Provavelmente, cabe à educação tal papel, concordando, mais uma vez, com o pensamento de Freire. Trata-se de "viver a própria existência como algo de unitário e verdadeiro, mas também como um paradoxo: obedecer para subsistir e resistir para poder pensar o futuro", o que significa assumir uma postura materialista e dialética que concebe a existência como "produtora de sua própria pedagogia" (SANTOS, 2001, p.116). Dessa forma, para Santos (2001, p.169) "até mesmo a partir da noção do que é ser um consumidor, poderemos alcançar a ideia de homem integral e de cidadão", já que "os homens, pela sua própria essência, buscam a liberdade" com diferentes intensidades, de acordo com o grau de compreensão do mundo que possuem (SANTOS, 2007, p.20).

De forma análoga, Freire adverte que a libertação não acontecerá por eventualidade, por concessão, mas será uma conquista efetivada pela práxis humana, que demanda uma luta ininterrupta. Ele não defende uma libertação enquanto ponto ideal, fora dos homens, ao qual inclusive eles se alienam. A liberdade é condição imprescindível ao movimento de busca em que estão inscritos os homens como seres inconclusos... "A libertação, por isto, é um parto [...] O homem que nasce deste parto é um homem novo que só é viável na e pela superação da contradição opressores-oprimidos, que é a libertação de todos" (FREIRE, 2002e, p.35). Freire almeja que o homem, consciente de sua situação de explorado, alcance o pleno entendimento de seu contexto, desenvolvendo forças capazes de superar essa exploração. Para tanto, propõe que, após refletirem sobre sua prática, homens e mulheres dialoguem entre si, libertando-se em conjunto. A realidade social, desigual e injusta, sendo resultado da ação humana, pode ser modificada:

A realidade social, objetiva, que não existe por acaso, mas como produto da ação dos homens, também não se transforma por acaso. Se os homens são os produtores desta realidade e se esta, 
na "inversão da práxis", se volta sobre eles e os condiciona, transformar a realidade opressora é tarefa histórica, é tarefa dos homens (FREIRE, 2002e, p.37).

Esta afirmação ratifica a crença freiriana na capacidade que homens e mulheres possuem de superar as suas "situações limite", a exploração constituída historicamente. Mostra, também, que transformar a realidade, implicando em libertar oprimidos e opressores, é a preocupação orientadora de seu engendramento da "pedagogia do oprimido, como pedagogia humanista e libertadora" (2002e, p.41), que tem dois momentos distintos. No primeiro, ainda dentro de uma realidade desigualmente injusta, logo, opressora, "os oprimidos vão desvelando o mundo da opressão e comprometendo-se, na práxis, com a sua transformação". Contempla, com razão, o termo "oprimido", pois a injustiça ainda existe, embora seja uma etapa na qual os homens, em processo de tomada de consciência, devam estar engajados na luta por sua humanização. $\mathrm{O}$ segundo momento, quando está "transformada a realidade opressora" (2002e, p.41), ou seja, em que homens e mulheres já estão em "processo de permanente libertação", a pedagogia deixa de ser apenas do oprimido e passa a ser a pedagogia de todos os homens, assegurando uma convivência pautada no amor, respeito mútuo e tolerância.

Sendo objeto e, ao mesmo tempo, sujeito do meio geográfico, agente determinante da sua transformação, cabe ao homem assumir a responsabilidade sobre os seus atos. Neste imperativo, reside a "ética universal do ser humano" que ao longo do processo de convivência social, pode tomar dois caminhos: um que a corrobora e outro que a nega. Consequentemente, é pela primeira possibilidade que uma educação libertadora precisa se pautar, o que implica construir, coletivamente, uma consciência crítica do presente vivido. É interdisciplinar, uma vez que sua efetivação inclui a compreensão da história, o esclarecimento dos "porquês" mais radicais do real percebido. Abriga, ainda, uma compreensão global da inter-relação das forças econômicas, sociais, espaciais e ideológicas, entre outras, que uma análise como esta requer. Afinal, como assevera Santos (2002a, p.20), "uma disciplina é uma parcela autônoma, mas não independente, do saber geral".

Enquanto realidade histórica, o mundo coloca o sujeito na perspectiva do espaço temporal, cujo dinamismo da feitura pode ser analisado no passado, no presente e no futuro. Inserido nessa dinâmica, aceita que a existência humana é devir e sua realização concebe o futuro como problema aberto à capacidade de realização, de todos e cada um. Nega, portanto, a passividade como vocação da espécie. O humano pode ser pensado como expressão que singulariza um ser, ao mesmo tempo em que constitui uma abertura dialética e dialógica, afirmativa da ideia de que é experimentando-se no mundo que ele se faz. "Ninguém nasce feito", destaca Freire (2001a, p.79), "vamos nos fazendo aos poucos, na prática social de que tomamos parte". Nesse sentido, viver humanamente é aventurar-se, ação que nos torna seres no mundo e com o mundo.

Portanto, o vir a ser do sujeito é parte de um processo educacional como aprendizagem permanente, que se realiza e se afirma em ato com o mundo. Afirmação que passa, necessariamente, pela identificação das situações limite, pois não é possível combater o indiscernível. Paulo Freire e Milton Santos, brasileiros e nordestinos, bacharéis em direito engajados politicamente desde cedo; presos e exilados pelo governo militar brasileiro; professores e intelectuais respeitados internacionalmente; críticos radicais da desigualdade social imposta pela globalização capitalista. Evidenciam-se tantas afinidades entre os dois que resolvemos indagar sobre a Geografia na obra de Paulo Freire.

\section{A GEOGRAFIA NA OBRA DE PAULO FREI- RE}

Leituras introdutórias revelam a presença de conceitos e mesmo de uma concepção metodológica ao referir-se diretamente a geografia escolar. Após uma análise mais aguçada, pensamos que é possível demonstrar a Geografia que permeia os escritos freirianos. Em termos de postura teórica e metodológica, há um nítido encontro entre a pedagogia de Freire, chamada Educação Problematizadora, e a Geografia Crítica, de base marxista, da qual Milton Santos é um dos principais expoentes.

Buscando identificar e caracterizar essa Geografia em Freire, optamos por adotar dois procedimentos complementares. De um lado, rastrear conceitos da ciência geográfica ao longo de sua obra, como espaço, lugar, território e região, além dos diferentes usos do vocábulo geografia. De outro, compreender as marcas implícitas ou explícitas das várias maneiras com que realiza uma abordagem afim com intencionalidades, métodos e concepções da Geografia. Mesmo de maneira preliminar, acreditamos que os dois caminhos permitem sustentar a afirmação de uma Geografia presente na obra de Paulo Freire.

Para a análise dos conceitos foram consideradas as seguintes obras, totalizando dezesseis: Ação cultural para a liberdade, A importância do ato de ler, Cartas a Cristina, Cartas a Guiné-Bissau, Conscientização, Educação e mudança, 
Extensão ou comunicação, Medo e ousadia, Pedagogia da autonomia, Pedagogia da esperança, Pedagogia da indignação, Pedagogia: diálogo e conflito, Pedagogia do oprimido, Política e educação, Por uma Pedagogia da pergunta e Professora sim, tia não. O quadro a seguir sintetiza os resultados obtidos.

Quadro 1. Conceitos da Geografia na obra de Paulo Freire

\begin{tabular}{|l|c|c|c|c|c|}
\hline \multirow{2}{*}{ OBRA } & \multicolumn{5}{|c|}{ CONCEITOS/NÜMERO DE VEZES } \\
\cline { 2 - 7 } & Geografia & Espaço & Regiäo & Lugar & Território \\
\hline Ação cultural para a liberdade & 01 & 10 & 01 & 38 & - \\
\hline A importância do ato de ler & 01 & 02 & 01 & 08 & - \\
\hline Cartas a Cristina & 12 & 46 & 12 & 35 & 03 \\
\hline Cartas a Guiné-Bissau & 12 & 02 & 08 & 23 & - \\
\hline Conscientização & - & 06 & 02 & 15 & 01 \\
\hline Educaçăo e mudança & - & 04 & - & 14 & 01 \\
\hline Extensão ou comunicação & - & 05 & 03 & 11 & - \\
\hline Medo e ousadia & - & 33 & - & 60 & 05 \\
\hline Pedagogia da autonomia & 02 & 27 & - & 17 & - \\
\hline Pedagogia da esperançă & 06 & 29 & 14 & 34 & 04 \\
\hline Pedagogia da indignaçăo & - & 14 & 01 & 18 & 01 \\
\hline Pedagogia: diálogo e conflito & - & 16 & 02 & 11 & - \\
\hline Pedagogia do oprimido & - & 12 & 01 & 38 & - \\
\hline Política e educacăo & - & 18 & - & 22 & - \\
\hline $\begin{array}{l}\text { Por uma Pedagogia da da } \\
\text { pergunta }\end{array}$ & 02 & 16 & 05 & 21 & - \\
\hline Professora sim, tia, não & 01 & 10 & 02 & 22 & - \\
\hline \multicolumn{1}{|c|}{ TOTAIS } & 37 & 250 & 52 & 387 & 15 \\
\hline
\end{tabular}

Fonte: Elaboração dos autores

Embora a utilização dos termos normalmente não esteja diretamente associada ao significado conceitual da ciência geográfica, de acordo com o quadro demonstrativo as obras Cartas a Cristina, Pedagogia da Esperança e Cartas a Guiné-Bissau, respectivamente, seriam as mais "geográficas" de Freire. Como exemplo de uso não relacionado ao conceito geográfico, lugar, várias vezes aparece como sinônimo de "em vez de" (em lugar de). A palavra "Geografia" aparece às vezes como campo do saber científico e disciplina na escola; descrição física dos contextos vividos, e, mais enfaticamente, na narrativa em que relaciona a experiência da fome com o ensino de uma Geografia enfadonha na escola:

Lembrava-me do tempo que gastava dizendo e redizendo, olhos fechados, caderno nas mãos: Inglaterra, capital Londres, França, capital Paris. Inglaterra, 'capital Londres. "Repete, repete que tu aprendes", era a sugestão mais ou menos generalizada no meu tempo de menino. Como aprender, porém, se a única geografia possível era a geografia de minha fome? A geografia dos quintais alheios, das fruteiras - mangueiras, jaqueiras, cajueiros, pitangueiras -, geografia que Temístocles - meu irmão imediatamente mais velho do que eu - e eu sabíamos, aquela sim, de cor, palmo a palmo (FREIRE, 2003, p.42).

Porém, em termos de associação com a Geografia, o texto de "À sombra desta mangueira" possui uma relação bastante intensa, principalmente devido à densidade das descrições que o autor faz dos seus lugares vivenciados historicamente. Já nas primeiras palavras a relação existencial com a natureza ganha destaque:

As árvores sempre me atraíram. As frondes arredondadas, a variedade do seu verde, a sombra aconchegante, o cheiro das flores, os frutos, a ondulação dos galhos, mais intensa ou menos intensa em função de sua resistência ao vento. As boas vindas que suas sombras sempre dão a quem a elas chega, inclusive a passarinhos multicores e cantadores. A bichos, pacatos ou não, que nelas repousam (FREIRE, 2000b, p.15).

Na mesma obra (p.20), compartilha com Milton Santos a relevância da dimensão técnica na construção da vida humana, ao considerar que "a passagem de suporte a mundo implica a invenção de técnicas e instrumentos que tornam mais fácil a intervenção no mundo". Em outro momento o texto (p.24) remete ao seu "primeiro mundo", o "quintal de casa, com suas mangueiras, cajueiros de fronde quase ajoelhando-se no chão sombreado". O quintal de sua infância traduz-se e se desdobra "em tantos outros espaços, não necessariamente outros quintais", e o considera como o seu "primeiro não-eu geográfico", referindo-se ao espaço existencial além do próprio corpo.

Em "A Educação na Cidade", Freire (2006, p.90) explica as dimensões de possibilidade que se fazem a partir da conjuntura espaço-temporal:

O homem e a mulher fazem a história a partir de uma dada circunstância concreta, de uma estrutura que já existe quando a gente chega ao mundo. Mas esse tempo e esse espaço têm que ser um tempo-espaço de possibilidade, e não um tempo-espaço que nos determina mecanicamente.

São muitas as marcas da Geografia nos textos de Freire, algumas das quais procuramos expor, respeitando os limites deste trabalho.

\section{CONSIDERAÇÕES FINAIS}

Salientamos que Paulo Freire e Milton Santos, pensadores contemporâneos, encontram-se para além dos elementos conceituais parcialmente evidenciados neste texto. $\mathrm{O}$ compromisso social, acompanhado pela seriedade teórica e epistemológica com que abordam suas áreas de estudo, Educação e Geografia, assim como a capacidade e o gosto pelo diálogo interdisciplinar o atestam. Utópicos, compartilham a negação radical do imobilismo e a crença na libertação como conquista dos sujeitos - cidadãos, em seu contexto - espaço vivencial. Como Santos (2007, p.161) adverte, "ficar prisioneiro do presente ou do passado é a melhor maneira para não fazer aquele passo adiante, sem o qual nenhum povo se encontra com o futuro".

A partir do diálogo entre eles e com eles, podemos nos voltar, revigorados, ao trabalho concreto de enfrenta- 
mento das contradições sociais, amparados na utopia de que um outro mundo é possível.

\section{REFERÊNCIAS BIBLIOGRÁFICAS}

FREIRE, Ana Maria Araújo. Paulo Freire: uma história de vida. Indaiatuba, SP: Villa das Letras, 2006.

FREIRE, Paulo. Conscientização: teoria e prática da libertação. São Paulo: Moraes, 1980.

FREIRE, Paulo. Aprendendo com a própria história Rio de Janeiro: Paz e Terra, 1987.

FREIRE, Paulo. Pedagogia da Autonomia. São Paulo: Paz e Terra, 1996.

FREIRE, Paulo. Pedagogia da Indignação: Cartas Pedagógicas e Outros Escritos. São Paulo: Unesp, 2000a.

FREIRE, Paulo. À Sombra desta Mangueira. São Paulo: Olho d'Água, 2000b.

FREIRE, Paulo. Pedagogia: diálogo e conflito. São Paulo: Cortez, 1985.

FREIRE, Paulo. Educação na Cidade. São Paulo: Cortez, 1991.

FREIRE, Paulo. Extensão ou Comunicação? São Paulo: Paz e Terra, 2001a.

FREIRE, Paulo. Política e Educação: ensaios. São Paulo: Cortez, 2001b.

FREIRE, Paulo. A importância do ato de ler. São Paulo: Cortez, 2001c.

FREIRE, Paulo. Ação Cultural para a Liberdade. São Paulo: Paz e Terra, 2002a.

FREIRE, Paulo. Educação e Atualidade Brasileira. São Paulo: Cortez; IPF, 2002b.

FREIRE, Paulo. Educação Como Prática da Liberdade. Rio de Janeiro: Paz e Terra, 2002c.

FREIRE, Paulo. Educação e Mudança. Rio de Janeiro: Paz e Terra, 2002d.

FREIRE, Paulo. Pedagogia do Oprimido. Rio de Janeiro: Paz e Terra, 2002e.

FREIRE, Paulo. Pedagogia da Esperança. São Paulo: Paz e Terra, 2002f.

FREIRE, Paulo. Professora Sim, Tia Não. São Paulo: Olho D'água, 2002g.
FREIRE, Paulo. Cartas a Cristina. São Paulo: Unesp, 2003.

FREIRE, Paulo. A educação na cidade. São Paulo: Cortez, 2006.

SANTOS, Milton. Por uma outra globalização: do pensamento único a consciência universal. Rio de Janeiro:

Record, 2001.

SANTOS, Milton. Entrevista com Milton Santos. São Paulo: Perseu Abramo, 2000.

SANTOS, Milton. O espaço do cidadão. São Paulo: EDUSP, 2007.

SANTOS, Milton. A natureza do espaço: técnica e tempo, razão e emoção. São Paulo: EDUSP, 2002a.

SANTOS, Milton. Por uma Geografia nova: da crítica da Geografia a uma Geografia crítica. São Paulo: EDUSP, 2002b.

STRECK, Danilo; REDIN, Euclides; ZITKOSKI, Jaime José (Org.). Dicionário Paulo Freire. Belo Horizonte: Autêntica, 2010 .

Notas de Fim:

1- As informações sobre Freire foram extraídas da obra Paulo Freire: uma história de vida, de Ana Maria Araújo Freire (2006).

\section{Correspondência dos autores:}

Sandro de Castro Pitano

e-mail: scpitano@gmail.com

Rosa Elena Noal

e-mail: rosa.noal@gmail.com

Artigo recebido em: 18/04/2016

Revisado pelo autor em: 25/08/2016

Aceito para publicação em: 05/10/2016 